\title{
Theory of Randomized Search Heuristics
}

Foundations and Recent Developments 
Editor-in-Chief: Francis Chin (The University of Hong Kong, Hong Kong)

Associate Editors: Marek Chrobak (University of California, USA)

Costas S. Illopoulos (University of London, UK)

Kazuo Iwana (Kyoto University, Japan)

Ming-Yang Kao (Northwestern University, USA)

This book series provides an up-to-date and reliable source of information from fundamental knowledge to emerging research areas related to theoretic computer science. The target audiences cover researchers, engineers, scientists, students and professionals.

Vol. 1: Theory of Randomized Search Heuristics: Foundations and Recent Developments edited by Anne Auger and Benjamin Doerr 
Series on Vol. 1

Theoretical Computer Science

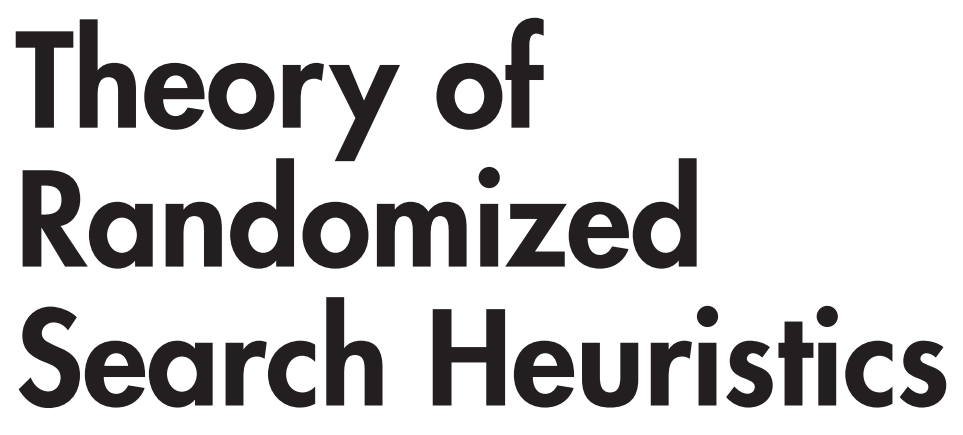

Foundations and Recent Developments

Editors

Anne Auger

INRIA, France

Benjamin Doerr

Max-Planck-Institut für Informatik, Germany 
Published by

World Scientific Publishing Co. Pte. Ltd.

5 Toh Tuck Link, Singapore 596224

USA office: 27 Warren Street, Suite 401-402, Hackensack, NJ 07601

UK office: 57 Shelton Street, Covent Garden, London WC2H 9HE

\section{British Library Cataloguing-in-Publication Data}

A catalogue record for this book is available from the British Library.

\section{Series on Theoretical Computer Science - Vol. 1 THEORY OF RANDOMIZED SEARCH HEURISTICS Foundations and Recent Developments}

Copyright (c) 2011 by World Scientific Publishing Co. Pte. Ltd.

All rights reserved. This book, or parts thereof, may not be reproduced in any form or by any means, electronic or mechanical, including photocopying, recording or any information storage and retrieval system now known or to be invented, without written permission from the Publisher.

For photocopying of material in this volume, please pay a copying fee through the Copyright Clearance Center, Inc., 222 Rosewood Drive, Danvers, MA 01923, USA. In this case permission to photocopy is not required from the publisher.

ISBN-13 978-981-4282-66-6

ISBN-10 981-4282-66-9

Printed in Singapore. 
To Ingo Wegener 
This page intentionally left blank 


\section{Preface}

Randomized search heuristics such as evolutionary algorithms, evolution strategies, genetic algorithms, simulated annealing or ant colony and particle swarm optimization are recognized as powerful optimization algorithms and play an important role in modern algorithmics nowadays. While their success in many application fields is undoubted, we have little theoretical understanding why and when these methods work well.

The theory of randomized search heuristics tries to answer these fundamental questions. In spite of being a young field, substantial advances have been made in the last years. In this book, the first one covering theoretical aspects of different randomized search heuristics, we aim at both giving an introduction to this field and presenting recent progress. By collecting important results spread over many different conference or journal papers so far, this book shall also serve as a reference for future research work.

The different chapters cover randomized search heuristics for discrete/combinatorial and continuous search spaces. Though single objective optimization is mainly addressed, one chapter is fully devoted to multiobjective optimization. Another chapter is dedicated to the famous NoFree-Lunch theorem.

We editors are deeply indebted to the contributors of this book. They did an outstanding job making their expertise easily accessible to a broad audience. We are thankful to the reviewers of the different chapters for their constructive careful reviews. Our deepest thanks also go to Liang Quan, Gregory Lee, and all other staff of World Scientific Publishing Co. for their help and patience. Finally, we are very happy that Ming-Yang Kao, associate editor of the book series on Theoretical Computer Science, suggested to write this book and provided the contact to the publisher.

This book is dedicated to Ingo Wegener, who much too early passed away on November 26, 2008. Without his pioneering work this field would have never gotten the maturity it now has. 
We hope that the reader enjoys this book. We are grateful for any comments and any notifications of (hopefully only very few) errors. We plan to set up a web-site to communicate them. Needless to say, any comment also helps improving a new edition of the book.

September 2010

Anne Auger and Benjamin Doerr 


\section{Contents}

Preface vii

1. Analyzing Randomized Search Heuristics: Tools from Probability Theory 1

Benjamin Doerr

2. Runtime Analysis of Evolutionary Algorithms for

Discrete Optimization

Peter S. Oliveto and Xin Yao

3. Evolutionary Computation in Combinatorial Optimization

Daniel Johannsen

4. Theoretical Aspects of Evolutionary Multiobjective Optimization 101 Dimo Brockhoff

5. Memetic Evolutionary Algorithms

Dirk Sudholt

6. Simulated Annealing

Thomas Jansen 
7. Theory of Particle Swarm Optimization

Carsten Witt

8. Ant Colony Optimization: Recent Developments in Theoretical Analysis

Walter J. Gutjahr

9. A "No Free Lunch" Tutorial: Sharpened and Focused No Free Lunch

Darrell Whitley and Jonathan Rowe

10. Theory of Evolution Strategies: A New Perspective Anne Auger and Nikolaus Hansen

11. Lower Bounds for Evolution Strategies

Olivier Teytaud

Subject Index 